\title{
Survival from Cecal Ligation and Puncture and the Formation of Fibrous Adhesions in the Peritoneal Cavity Depend on Endogenous Tumor Necrosis Factor
}

\author{
B. Echtenacher ${ }^{1,2}$, W. Falk ${ }^{1.3}$, D. N. Männel ${ }^{1,2}$, and P. H. Krammer ${ }^{1}$
}

The purpose of this study was to clarify the role of tumor necrosis factor (TNF) in the recovery from peritonitis caused by sublethal cecal ligation and puncture (CLP). TNF is thought to play a beneficial role because pretreatment of mice with lipopolysaccharide (LPS) or TNF increased the survival rate of injected animals $[1,2]$. To investigate the contribution of endogenous TNF to recovery from peritonitis we tested the effect of a neutralizing rat anti-mouse TNF monoclonal antibody (V1q) [3]. We showed that as little as $20 \mu \mathrm{g} \mathrm{V1q} /$ mouse effectively prevented lethal shock of the animals caused by subsequent injection of $400 \mu \mathrm{g}$ LPS, demonstrating the in vivo efficacy of the antibody. Lethal bolus injections of LPS or bacteria are used as sepsis models by many investigators [4]. In these models the potentially lethal reactions (production of large amounts of interleukin-1 and TNF) of the organism may develop faster than the regulatory inflammatory reactions (e.g., acute-phase proteins, glucocorticoids). Therefore, these models may represent only part of the whole inflammatory repertoire [5]. We preferred CLP as a sepsis model because of its slower development and the presence of a septic focus $[6,7]$.

For sublethal CLP 10- to 14-week-old $\mathrm{C} 3 \mathrm{H} / \mathrm{HeN}$ mice were anesthetized, and the abdominal skin was shaved. A $0.7-\mathrm{cm}$ midline incision was made. The cecum was exteriorized and filled with feces by milking stool back from the ascending colon. The cecum was ligated below the ileocecal valve and punctured once with a $0.9 \times 40 \mathrm{~mm}$ needle. Gentle pressure was applied on the ligated cecum to exteriorize a small amount of feces. The cecum was then returned to the peritoneal cavity and the incision closed with clamps and Histoacryl blue (enbucrilate) tissue glue. Mice were observed for at least 2 weeks.

In sublethal CLP intraperitoneal injection of $0.1 \mathrm{mg} \mathrm{V1q} \mathrm{directly} \mathrm{and} \mathrm{up} \mathrm{to}$ $8 \mathrm{~h}$ after induction of experimental peritonitis lead to death of the animals within 1-3 days. Only if Vlq was injected $16 \mathrm{~h}$ after CLP about half of the mice survived (Fig. 1). To correlate this result with production of endogenous TNF the serum of untreated CLP mice was tested for biologically active TNF. During the first $20 \mathrm{~h}$ no TNF was detectable.This may be explained by the assumption

1 German Cancer Research Center, Im Neuenheimer Feld 280, 6900 Heidelberg, FRG

2 New address: Klinik der Universität Regensburg, Pathologie/Tumorimmunologie, Franz-JosefStrauß-Allee, 8400 Regensburg, FRG

${ }^{3}$ Medizinische Klinik I, Universität Regensburg, Franz-Josef-Strauß-Allee, 8400 Regensburg, FRG 


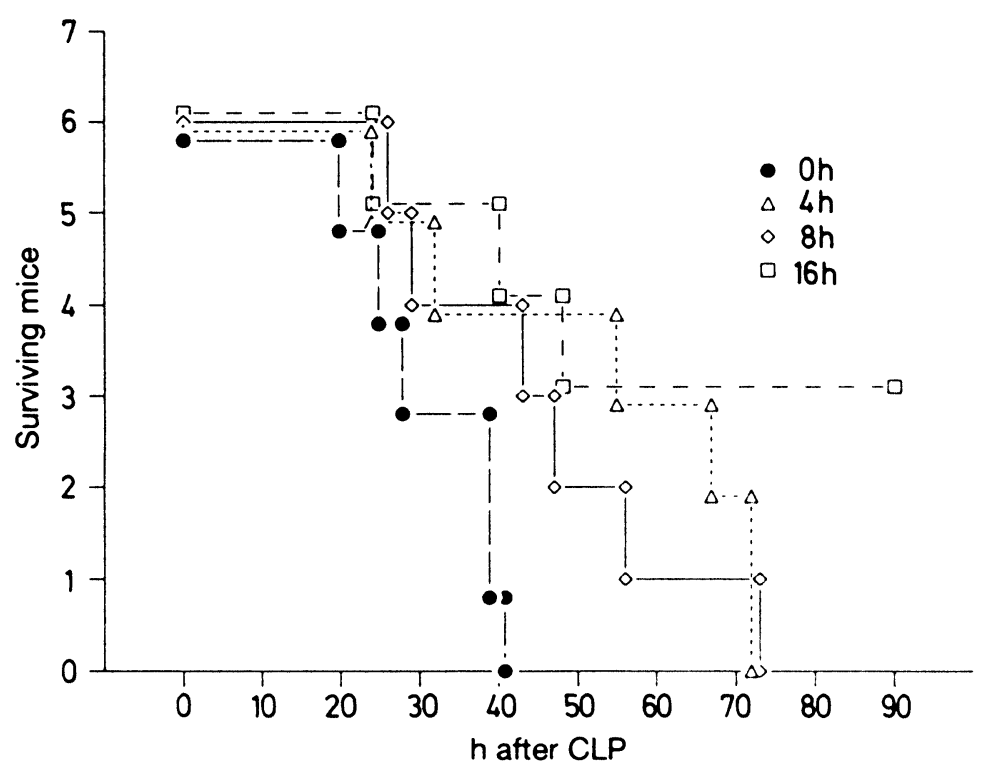

Fig.1. Requirement of TNF for survival from CLP during the first $8 \mathrm{~h}$ of peritonitis: $0(O), 4(\triangle), 8$ $(\diamond)$, and $16 \mathrm{~h}(\square)$ after CLP mice were injected with $100 \mu \mathrm{g}$ monoclonal antibody $\mathrm{V} 1 \mathrm{q}$ in $0.2 \mathrm{ml}$ phosphate-buffered solution. These injections were repeated $24 \mathrm{~h}$ after CLP

that TNF is produced and consumed only locally at the punctured cecum. This was in line with findings by other investigators who also did not detect TNF after CLP even when they used lethal CLP or related models [8].

Surviving mice that were killed 2 weeks after CLP showed an encapsulated cecum and strong fibrous adhesions. Examination of mice that had died from CLP after V1q injection showed no fibrous adhesions to the cecum 1-3 days after CLP. To determine any correlation between the time of declining lethality after V1q injection and the occurrence of fibrous adhesions treated mice were killed at different times after CLP. There were no adhesions seen after $10 \mathrm{~h}$. After $15 \mathrm{~h}$ fibrous adhesions became visible, and after $18 \mathrm{~h}$ such adhesions were pronounced (Fig. 2).

The lethal effect of monoclonal antibody V1q was prevented by injection of recombinant mouse TNF (rmTNF). V1q was injected immediately after CLP and rmTNF $1 \mathrm{~h}$ later. Remarkably, the same amount of rmTNF that saved CLP mice from lethal V1q injection killed CLP mice if rmTNF was injected without previous V1q administration. Therefore, a certain beneficial TNF concentration during CLP-induced peritonitis may have to be maintained because elimination of endogenous TNF or additional exogenous TNF would be lethal.

These observations may be explained by known properties of TNF. During the early phase of peritonitis endogenous TNF may stimulate nonlymphoid cells such as granulocytes and macrophages to ingest bacteria. TNF may enhance the procoagulant activity of the endothelium and mesothelium [9]. In addition, TNF may inhibit fibrinolysis [10]. Thus, adhesions of surrounding tissue (omentum, intestines) to the cecum are favoured by TNF. TNF production must 

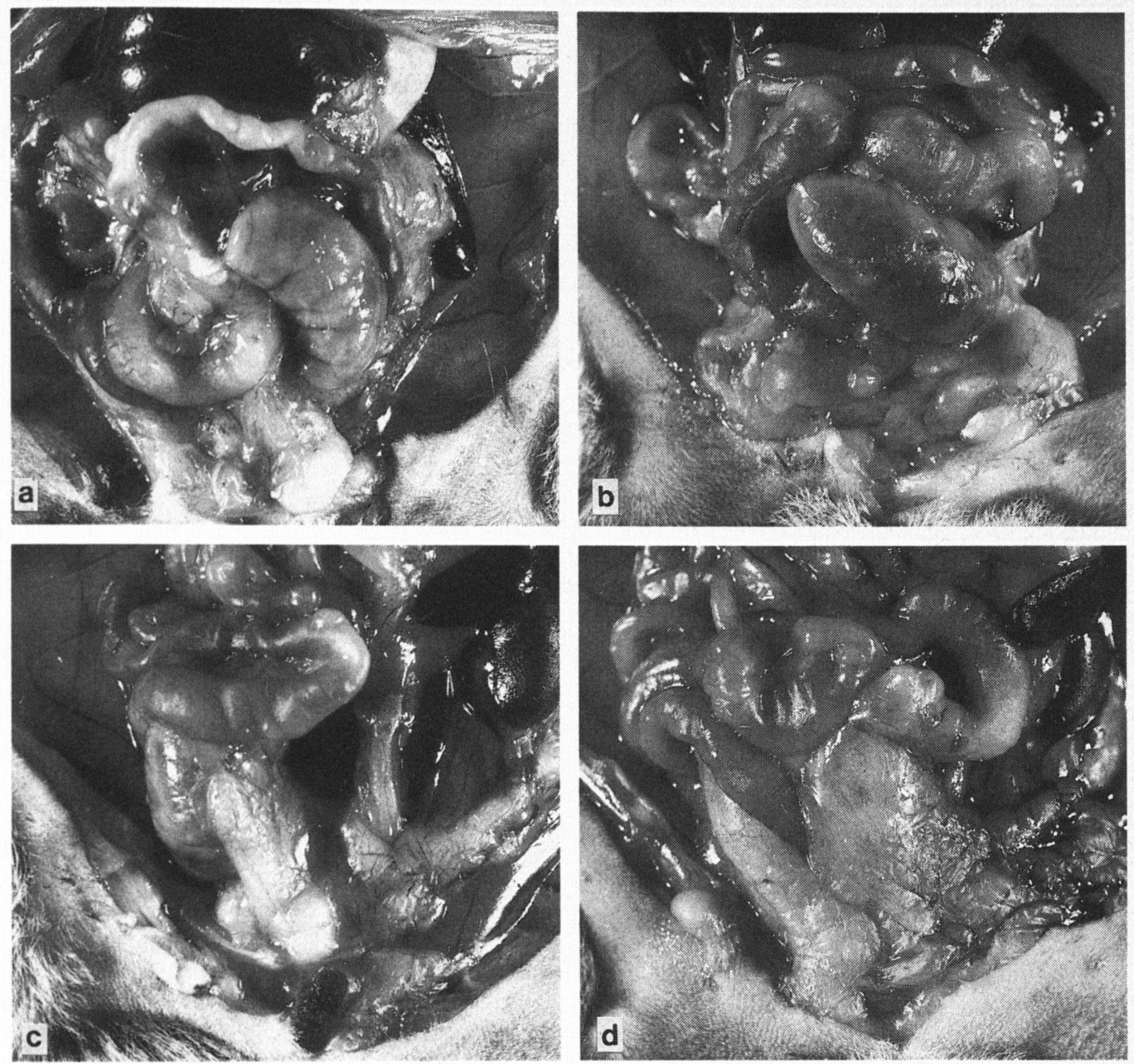

Fig.2a-d. The cecum of $\mathrm{C} 3 \mathrm{H} / \mathrm{HeN}$ mice at different times after CLP and intraperitoneal injection of anti-TNF monoclonal antibody V1q or Phosphate-buffered solution (PBS) only. a $18 \mathrm{~h}$ after CLP and injection of $100 \mu \mathrm{g} \mathrm{V1q}$. No adhesions at the cecum. b $42 \mathrm{~h}$ after CLP and injection of $100 \mu \mathrm{g}$ V1q. No adhesions at the cecum. $18 \mathrm{~h}$ after CLP and injection of $100 \mu \mathrm{l}$ PBS. Adhesions (intestine, omentum) at the cecum. d $42 \mathrm{~h}$ after CLP and injection of $100 \mu \mathrm{g}$ V1q. The cecum is covered completely by adhesions of the intestine and omentum

be tightly controlled in order to avoid disseminated intravascular coagulation and vascular leakage. One possibility is the control of TNF secretion through protease inhibitors which may prevent the cleavage of membrane TNF from the cell surface [11]. TNF increases interleukin-6 concentration in the blood, and this cytokine enhances synthesis of acute-phase proteins, some of which are protease inhibitors [12]. This mechanism may also be effective in other cases in which serum TNF was not detectable but essential for survival because antiTNF antibodies caused or accelerated the death of the infected animals (e.g. Listeria, bacille Calmette-Guérin, Leishmania) $[13,14,15,16]$. In summary, these data indicate that the administration of anti-TNF antibodies in sepsis may be deleterious rather than beneficial. 


\section{References}

1. Urbaschek B, Ditter B, Becker K-P, Urbaschek R (1984) Protective effects and role of endotoxin in experimental septicemia. Circ Shock 14:209

2. Sheppard BC, Fraker DL, Norton JA (1989) Prevention and treatment of endotoxin and sepsis lethality with recombinant human tumor necrosis factor. Surgery 106:156

3. Echtenacher B, Falk W, Männel DN, Krammer PH (1990) Requirement of endogenous tumor necrosis factor/cachectin for recovery from experimental peritonitis. J Immunol 145:3762

4. Beutler BA, Milsark IW, Cerami A (1985) Passive immunization against cachectin/tumor necrosis factor (TNF) protects mice from the lethal effects of endotoxin. Science 229:869

5. Luedke CE, Cerami A (1990) Interferon- $\gamma$ overcomes glucocorticoid suppression of cachectin/tumor necrosis factor biosynthesis by murine macrophages. J Clin Invest 86:1234

6. Wichterman KA, Baue AE, Chaudry IH (1980) Sepsis and septic shock -a review of laboratory models and a proposal. J Surg Res 29:189

7. Moss NM, Gough DB, Jordan AL, Grbic JT, Wood JJ, Rodrick ML, Mannick JA (1988) Temporal correlation of impaired immune response after thermal injury with susceptibility to infection in a murine model. Surgery 104:882

8. Evans GF, Snyder YM, Butler LD, Zuckerman SH (1989) Differential expression of interleukin1 and tumor necrosis factor in murine septic shock models. Circ Shock 29:279

9. Van Hinsbergh VW, Kooistra T, Scheffler MA, Van Bockel JH, Van Muijen GN (1990) Characterization and fibrinolytic properties of human omental tissue mesothelial cells. Comparison with endothelial cells. Blood 75:1490

10. Medcalf BL, Kruithof EKO, Schleuning W (1988) Plasminogen activator inhibitor 1 and 2 are tumor necrosis factor/cachectin-responsive genes. J Exp Med 168:751

11. Niehoerster M, Tiegs G, Schade UF, Wendel A (1990) In vivo evidence for protease-catalysed mechanism providing bioactive tumor necrosis factor alpha. Biochem Pharmacol 40:1601

12. Heinrich PC, Castell JV, Andus T (1990) Interleukin-6 and the acute phase response. Biochem J 265:621

13. Nakane A, Minigawa T, Kato K (1988) Endogenous tumor necrosis factor (cachectin) is essential to host resistance against Listeria monocytogenes infection. Infect Immun 56:2563

14. Havell EA (1987) Production of tumor necrosis factor during murine listeriosis. J Immunol 139:4225

15. Kindler V, Sappino A-P, Grau GE, Piguet P-F, Vassalli P (1989) The inducing role of tumor necrosis factor in the development of bactericidal granulomas during BCG infection. Cell 56:731

16. Titus RG, Sherry B, Cerami A (1989) Tumor necrosis factor plays a protective role in experimental murine cutaneous leishmaniasis. J Exp Med 170:2097 